\title{
On the front line of community-led air quality monitoring
}

\author{
Authors: Muki Haklay ${ }^{1}$ and Irene Eleta ${ }^{2}$ \\ ${ }^{1}$ Extreme Citizen Science group, Department of Geography, University College London \\ (UCL), UK \\ 2 ISGlobal, Centre for Research in Environmental Epidemiology (CREAL), Barcelona, \\ Spain; Universitat Pompeu Fabra (UPF), Barcelona, Spain; CIBER Epidemiología y Salud \\ Pública (CIBERESP), Spain
}

\begin{abstract}
In this chapter, we explore the potential of community-led air quality monitoring. Community-led air quality monitoring differs from top-down monitoring in many aspects: it is focused on community needs and interests and a local problem and, therefore, has a limited geographical coverage as well as limited temporal coverage. However, localised air quality monitoring can potentially increase the spatial and temporal resolution of air quality information if there is a suitable informationsharing mechanism in place: information from multiple community-led activities can be shared at the city scale and used to augment official information. At the core of the chapter, we provide a detailed experiential description of the process of urban air quality practice, from which we draw our conclusion. We suggest that accessible and reliable community-led air quality monitoring can contribute to the understanding of local environmental issues and improve the dialogue between local authorities and communities about the impacts of air pollution on health and urban and transport planning.
\end{abstract}

\section{Introduction}

In a way, the challenge of ensuring that city air is breathable is a consistent feature of city governance and management. Early regulations to prohibit the burning of coal because it was "prejudicial to health" appeared in London in 1273 (Laundon 1967), though were later relaxed. The systematic governance of air pollution through regulations and enforcement started to appear in the second part of the $19^{\text {th }}$ century, as a result of the increased industrialisation and use of coal (Lowenthal 1990; Heidorn 1978). Air quality is also intimately linked to the modern awareness of environmental issues and to government action to address it. A prime example of it is the December 1952 smog event in London, which killed about 4000 people, leading to a regulatory response and the Clean Air Act of 1956 (Fenger 2009). Beyond the UK, air quality regulations are some of the early examples 
of the European Union (EU) environmental regulations, dating back to 1979 with regulations to address transboundary pollution (Kuklinska et al. 2015).

Yet, from the mid-1950s, when public awareness of air pollution and its harmful health impacts was raised, until the 1990s, air quality issues were addressed through top-down regulations, usually mandating a centralised network of monitoring stations, run under the control of public authorities, to check that progress was being made. Addressing such environmental concerns through top-down scientific management was somewhat expected, since environmental problems require expertise from multiple areas such as atmospheric sciences, public health, toxicology, chemistry and so on, and every measure to address environmental problems requires a discussion with many stakeholders - from community leaders to various industries that need to be involved in addressing pollution issues, to health workers. ${ }^{1}$ Thus, environmental decision making was seen as an area that required scientific expertise and, therefore, involved experts and decision makers without much engagement with the public (Haklay 2017).

Since the late 1980s, there has been a growing awareness of the importance of public engagement in the process of environmental decision making (see Haklay 2017). The demand for public participation in environmental decision making in a meaningful way emerged in the 1980s, receiving a notable mention in the 1987 Brundtland report (WCED and Brundtland 1987) and the acceptance of the sustainable development principles at the Rio conference in 1992. Significantly, the principle of public participation in decision making received due attention in the outcomes of the Earth Summit, with Principle 10 which highlights access to information, participation in decision making and access to justice. As the 1990s progressed, the Principle was enshrined in conventions and laws (e.g. the Aarhus Convention in 1998), turning Principle 10 into practical commitments by government and the subsequent EU directives that implement it -2003/4/EC and 2003/35/EC (see Haklay 2003). Efforts to release environmental information became common during this period and, since air monitoring systems were already in place, they became one of the early sources of environmental information that was published, publicly, on the Internet some 20 years ago, with repositories such as the UK air quality archive (which maintains data going back to the 1970s) providing its information over the web, and many other systems following these early examples.

It is noteworthy that, although the Aarhus Convention and Principle 10 clearly call for engaging the public in the environmental decision making process, they are not challenging the underlying assumption of who will produce the information. The opening declaration of Chapter 40 in Agenda 21 (the official outcome of the Rio conference), which is dedicated to information for decision making, stated:

"In sustainable development, everyone is a user and provider of information considered in the broad sense. That includes data, information, appropriately packaged experience and knowledge. The need for information arises at all levels, from that of senior decision makers at the national and international levels to the grass-roots and individual levels." (United Nations 1992)

\footnotetext{
${ }^{1}$ Notably, the Clean Air Council that was created following the 1956 legislation included representatives from local government and industry (e.g. Guinness, coal producers, Unilever), a public health specialist and national trade union representative, engineers and scientists.
} 
However, the rest of Chapter 40 and Principle 10 assumed that environmental information was produced by experts and the public was granted access to it in order to facilitate participation in decision making. It took more than a decade until the suggestion that the public could actively participate in the generation of environmental information was declared by leading environmental information experts (see McGlade 2008).

Yet, the 1990s also saw another form of environmental awareness, with the emergence of environmental justice as an important facet of environmental policy. The evidence for different exposure to environmental harms as a result of racial discrimination appeared in the early 1990s (Bullard and Wright 1993). By the end of the decade, methodologies to support community-led measurement of the harms that they were exposed to started to appear. Community-led environmental monitoring is now recognised as a specific part of the wider landscape of public participation in collecting and sharing environmental information - which is now termed citizen science (Bonney et al. 2014; Haklay 2013).

Most citizen science is contributory (Shirk et al. 2012), which means that scientists set the project and define the data collection protocols and participants, who are not professional scientists, join the project and assist the scientists in data collection or in basic analysis tasks. For example, one of the earliest examples of an activity that used the term "citizen science" was carried out in 1989 by the Audubon society in the United States, which provided 225 volunteers from across the country with equipment and guidance so they could collect rain samples to monitor acid rain. The project was led by scientists who guided participants in how to contribute their observations and time.

In contrast, community-led environmental monitoring activities have emerged from concerns of a community member or members. Here, again, the scientific nature of environmental decision making plays a major part. Since the environmental problem can be discovered through scientific measurement, and addressed through the use of the resulting information in discussions with authorities, the use of scientific methods that engage community members in information collection and analysis is becoming a clear route to address the concerns. Air and water monitoring are good examples of this - although community members may suspect that a water source is contaminated, or that the level of chemicals in the air is leading to ill health, only through laboratory analysis of water samples can they provide evidence for this. The nature of community-led projects is that they address localised problems, rely on local knowledge and use community resources to carry out the investigation. By resources, we mean the availability of people from the community to carry out measurements at different locations throughout the day, using residents' balconies or windowsills as a basis for equipment, or possibly raising money from a large group of residents to pay for laboratory costs.

Examples of community-led air pollution measurement efforts to collect the scientific data needed to make the regulatory case started to emerge in the 1990s (Corburn 2005). This, in part, was made possible by the proliferation of equipment for sensing the environment as it became part of routine, large-scale monitoring programmes at local and national levels. This proliferation and reduction in costs meant that instruments and science measurements came within the reach of non-governmental organisations and community groups. An example of this is the Global Community Monitor - an organisation that, since 1998, has developed a method to allow communities to monitor air quality near polluting factories (Scott and Barnett 2009). The sampling is done by members of the affected community using widely available plastic buckets and bags, followed by analysis in an air quality laboratory with the 
appropriate knowledge and ability to analyse the sample. Finally, the community is provided with guidance on how to understand the results. This activity is termed 'Bucket Brigade' and is used across the world in environmental justice campaigns: for example, in the struggle of local African-American residents in Diamond, Louisiana, against a polluting Shell Chemical plant (Ottinger 2010).

Another community tool for air monitoring is a passive diffusion tube. This is a simple, yet widespread tool for local level air quality monitoring. Passive diffusion tubes or, simply, diffusion tubes sense through a simple mechanism (see Figure 1A). A plastic tube is sealed with a rubber cup, within which there is a metal mesh on which there is a chemical absorbent of a known quantity (Figure 1B). Figure 1 shows a nitrogen dioxide $-\mathrm{NO}_{2}-$ diffusion tube, and the white cup, which is used for transportation to and from the laboratory, is removed to allow the absorbent to react with the specific pollutant that is being measured (in other types of diffusion tubes for other pollutants the white cup acts as a filter and is not removed). Once the measurement period ends, the tube is sent to the laboratory, and the concentration of the pollutant can be calculated. Diffusion tubes are easy to use - they require simple installation that does not need much more than a stepladder and brief training; do not require any maintenance while installed; gradually became cheaper to build and analyse; are evaluated in an accredited laboratory that can ensure data quality; and are also well established as a tool that has been used by local authorities to monitor pollution since their invention in the 1970s by Edward Palmes (Sella 2016). These characteristics make them highly suitable for community-led air monitoring, and they have been in use in community-led campaigns in Sheffield, UK, since 1998, in collaboration with the city's authorities (Parry and Rimmington 2013). The Sheffield East End Quality of Life Initiative explicitly links health with social and environmental justice. Its air quality monitoring involves using tubes in five locations and has influenced a range of local decision making, including halting a planning process for an increase in the size of a major supermarket in the area due to concerns about increased traffic and the evidence from the monitoring effort that the area is already exposed to high levels of traffic-related pollution. Moreover, it continually monitors the literature and publications in the area of linkage between health, air pollution and noise and, since March 2013, has published regular summaries of the latest research on a monthly basis, thus providing its community with an accessible summary of the latest findings (see http://www.sheffieldeastend.org.uk/Reports.htm).

This type of community-led monitoring is the topic of this chapter. In the next section, we briefly review several cases of the application of high-density diffusion tube campaigns in London. We then turn to the core of the chapter, and a detailed account of the experience of carrying out a community-led diffusion tube campaign. Finally, we summarise with some of the lessons learnt from our engagement with the process. 
Figure 1-(A) An assembled passive diffusion tube for measuring nitrogen dioxide; (B) The parts of the diffusion tube - the grey cup contains the absorbent and the white cup is taken off during the measurement period.

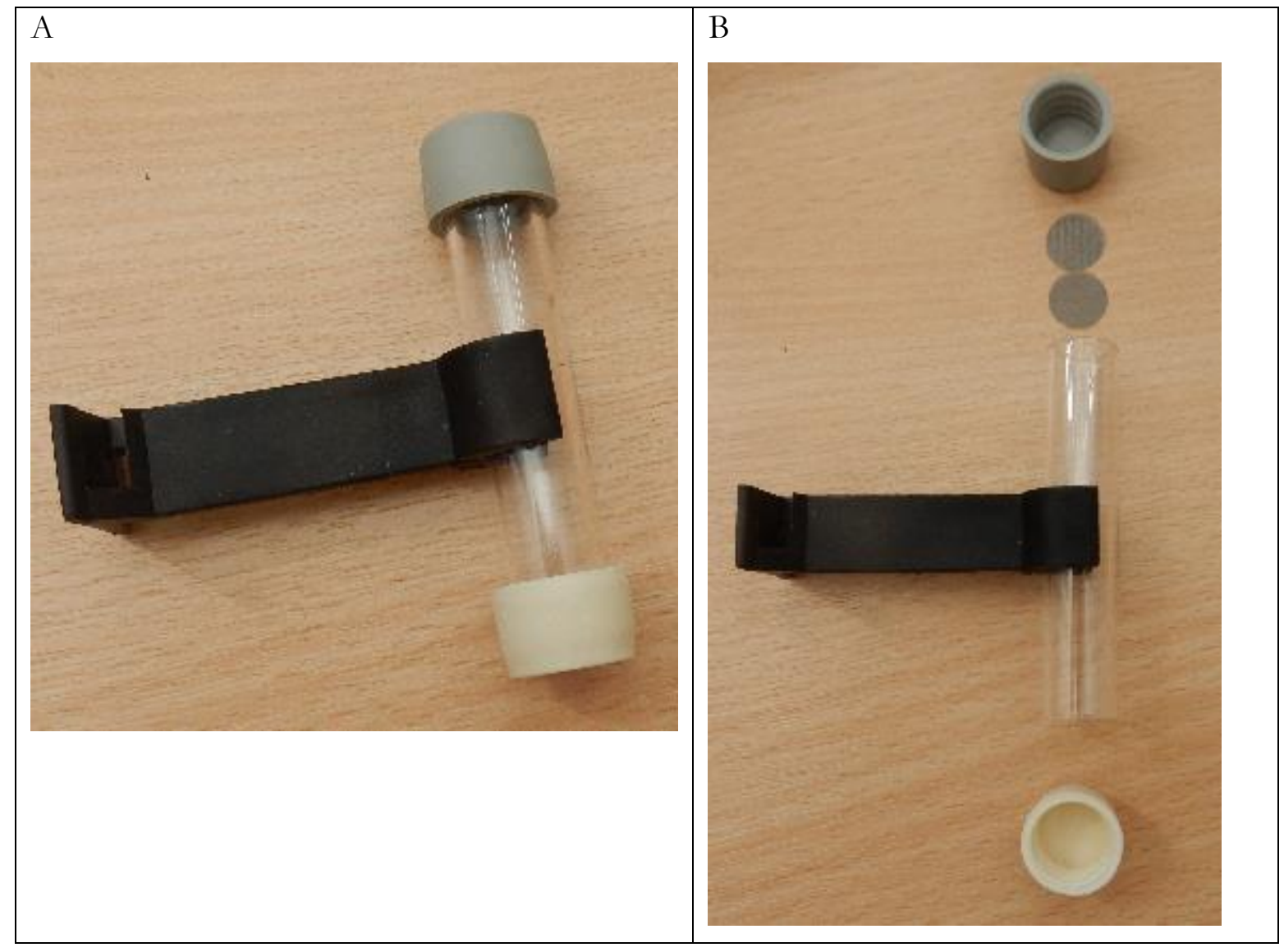

\section{Mapping for Change diffusion tube campaigns}

By 2010, the cost of diffusion tubes had continued to drop and it became possible to provide communities with a larger number of passive diffusion tubes that they could install in a dense network of tubes over a period of a month or several months, and therefore reveal the localised pollution picture. Mapping for Change, a social enterprise that was created by UCL and London 21 Sustainability Network, seized the opportunity to use diffusion tubes that became available within the Open Air Laboratories air pollution work (Tregidgo et al. 2013) and on the Pepys Estate in London.

The Pepys Estate in Deptford, South London, is a predominately 1960s housing estate on the banks of the Thames, characterised by tower blocks and social housing. Situated near a busy thoroughfare and surrounding an industrial site, the estate suffers a variety of urban environmental issues. Following a noise pollution study of a local scrapyard in 2008, residents, in 2010, expressed concerns over local air quality and wanted to assess how good or poor the air quality was. They had particular concerns over the mechanical break-up of vehicles and large goods vehicles servicing the scrapyard, as well as local traffic, which were seen as potential sources of pollution. The possible impact of a planned housing development further heightened their desire to assess local air quality. The survey was 
initiated with the Pepys Community Forum and commissioned by London Sustainability Exchange (LSx), a charity geared towards creating a more sustainable London.

After a meeting in the local community centre, Mapping for Change provided residents with instructions and survey equipment to carry out their investigations. The area of the estate was divided up into 100-metre grids to obtain a good distribution of samples taken.

Activities commenced with a series of diffusion tubes being set out on lampposts around the area. Wipe samples were taken to assess the quantity and type of metals being deposited on vertical surfaces. Ozone levels were measured using Eco-badge ${ }^{\mathrm{TM}}$ ozone detection kits (see Figure 2), and leaf samples were collected and analysed by Lancaster University. All the data collected was analysed and compiled into a series of maps. A public meeting was held to provide feedback on the findings. As a result, the local authority (Lewisham) installed diffusion tube monitoring devices at the main junctions identified by the project as having higher levels of $\mathrm{NO}_{2}$. Levels of $\mathrm{NO}_{2}$ in London are largely from vehicle exhausts and are also a strong indicator of the presence of other air pollutants derived from vehicle emissions. The council also installed a PM10 particulate monitoring station in the neighbourhood to monitor the local situation. Previously, the closest fixed monitoring station was just over a kilometre away.

Figure 2-Testing Eco-badge ozone detection kits on the Pepys Estate.

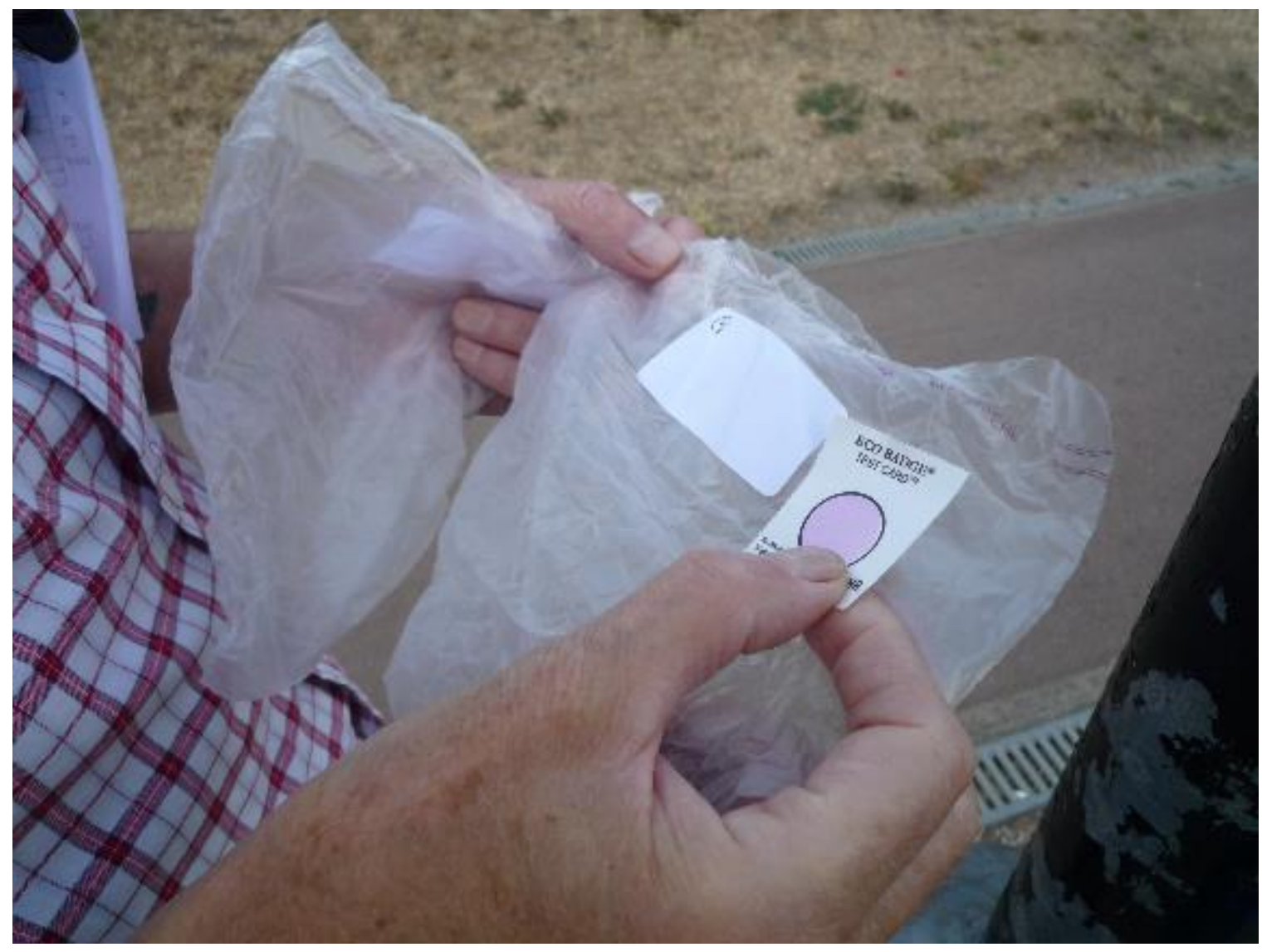


Of the methodologies that were used at the Pepys Estate, the diffusion tubes proved the most effective in terms of communicating with local decision makers as well as installation and confidence in the quality of the data.

A year later, as part of the project EveryAware (everyaware.eu), which was dedicated to participatory sensing and collective awareness, the use of diffusion tubes was developed further. The EveryAware project was set to develop real-time, portable air quality sensors, but in the early stages of the project there was a need to evaluate the level of interest among the public in the area of participatory monitoring. The aim was to provide communities with a way to measure air quality using low-technical methods that could be replicated easily and would engage all sectors of the community. A number of interested groups and individuals concerned about harmful levels of air pollution came forward via Twitter and through local community events and talks held at seminars. This led to a pilot that comprised seven locations across London and involved residents from Putney and Highbury and volunteers from Sustrans, a charity promoting sustainable transport.

Each community had slightly different motivations for wanting to carry out the investigation, which were explored in the initial discussion. The Putney Society had long been concerned about poor air quality in the area, which had consistently breached EU limits for $\mathrm{NO}_{2}$ and PM10. Monitoring activities in Highbury were led by members of the local Green Party who had been lobbying for $20 \mathrm{mph}$ zones in the area. In addition, communities wanted reliable localised data, which they could use to lobby local government, raise awareness, generate a better understanding of the issues and with which they could compare other relevant datasets. Sustrans, a sustainable transport charity, was keen to collect data to demonstrate the difference in pollution levels between routes not accessible to motorised vehicles and adjacent roads.

$\mathrm{NO}_{2}$ was selected as the focus, primarily because of the affordability of the monitoring equipment. Levels of $\mathrm{NO}_{2}$ largely arise from vehicle exhausts in London and are also a strong indicator of the presence of other air pollutants derived from vehicle emissions. In each location, a series of diffusion tubes, used to measure $\mathrm{NO}_{2}$ levels, were set out across the area. Based on lessons from previous studies, the areas were divided up into grid squares to ensure there was sufficient coverage; Putney, with a total of 38 sites, had the most monitoring locations. After a period of four weeks, the diffusion tubes were collected and analysed and the results mapped for each location. The results from both Putney and Highbury indicated that levels along the main road network were up to $75 \%$ higher than EU limits for the period. They also highlighted several residential back-roads used as 'rat runs' and, therefore, showing high levels of pollution. The remaining five monitoring locations across London each comprised one of London's Greenways (safe, quiet routes through parks, green spaces and streets with light traffic) compared with an adjacent busy road. The results showed significantly higher $\mathrm{NO}_{2}$ levels on the roads compared with the Greenways, despite their close proximity.

In addition to these studies, a year-long community-led monitoring was carried out on the Barbican Estate in Central London, and a six-month, multisite study was carried out with communities in London. Among the outcomes of the Barbican study, participating residents made suggestions to the City of London Corporation, which is the local authority of the area. These suggestions included aspects of urban planning and transportation, like extending the Ultra Low Emissions Zone, only allowing green buses, creating green areas and living walls, adjusting the phasing of traffic lights, introducing penalties for idling taxis, 
delivery vehicles and buses, and closing or improving the ventilation of the Beech Street tunnel (Francis and Stockwell 2015).

In December 2015, Mapping for Change ran a crowdfunding campaign to support community-led air quality projects, raising enough funding to support six communities. One of these was in the vicinity of University College London's main campus, in Somers Town, near Euston and King's Cross railway stations in central London. We now turn to the experience of community-led monitoring of one of the authors (Irene).

\section{On the ground - Somers Town study}

A cold wind was bringing dark clouds over London on that Wednesday morning of March. I hastened to enter University College London. In one of the offices - an open space full of desks - researchers and doctoral students were already busy at their computers; this is the main office that is shared by Mapping for Change and the Extreme Citizen Science group.

I crossed the main room, heading towards the kitchen. As Louise Francis, the co-founder and managing director of Mapping for Change had told me, I looked under the counter on the right, where I found a small fridge. Inside, Louise had left a zipped plastic bag with two diffusion tubes. I put them in my backpack and walked quickly to Euston train station.

I passed Euston train station and I took out a map of the Somers Town neighbourhood. It was a printed version of the Mapping for Change visualisation - the Community Maps system - of the neighbourhood, with numbered spots on it.

During the previous weeks, I had witnessed an email exchange between Louise and Tracey, ${ }^{2}$ one of the Somers Town residents who had taken the lead of monitoring air pollution in the neighbourhood. Tracey and other residents had chosen ten locations where they wanted to measure $\mathrm{NO}_{2}$ levels. They explained the characteristics and reasons for choosing these particular spots: crossroads with a lot of traffic in a residential area, in front of schools, in a park, etc. They were using their knowledge of the area and their understanding of the way they use it - either as the route to school or the playground in the afternoon - to consider where the information will help them most. Louise suggested adding another two locations close to main roads, so as to understand the scale of pollution in main thoroughfares nearby. Initially, Tracey and her team only had ten diffusion tubes and they chose ten spots carefully. Louise decided to give them two additional diffusion tubes to include her suggested spots, which I was carrying that morning to Somers Town. My map had twelve numbered marks, where the diffusion tubes would be placed.

The wind was getting colder and the sky was darkening. After passing the bustling surroundings of the train station, Somers Town looked relatively quiet. I wandered for a few minutes up and down a street until I asked an elderly resident who was walking his dog for the exact address. He pointed to a white apartment building.

It was almost $10 \mathrm{am}$ and I rang the doorbell. Tracey and I were introduced to each other for the first time. She looked young and energetic. She was getting ready: she had a bag full of diffusion tubes, tube holders, a laptop, a mobile phone, a notebook, a pen, scissors, white stickers about the activity and a ladder.

\footnotetext{
${ }^{2}$ Name changed for ethical reasons.
} 
Tracey, her friend and I went out to the street and joined two other neighbours for a team photo. By then, an intermittent drizzle announced that the weather was not going to be cooperative. We started by a lamppost next to a school, at a crossing of streets. Using the ladder, Tracey and her friend tightened the plastic belt to the lamppost.

Figure 3-Installing a diffusion tube in Somers Town and leaving a note about the activity.
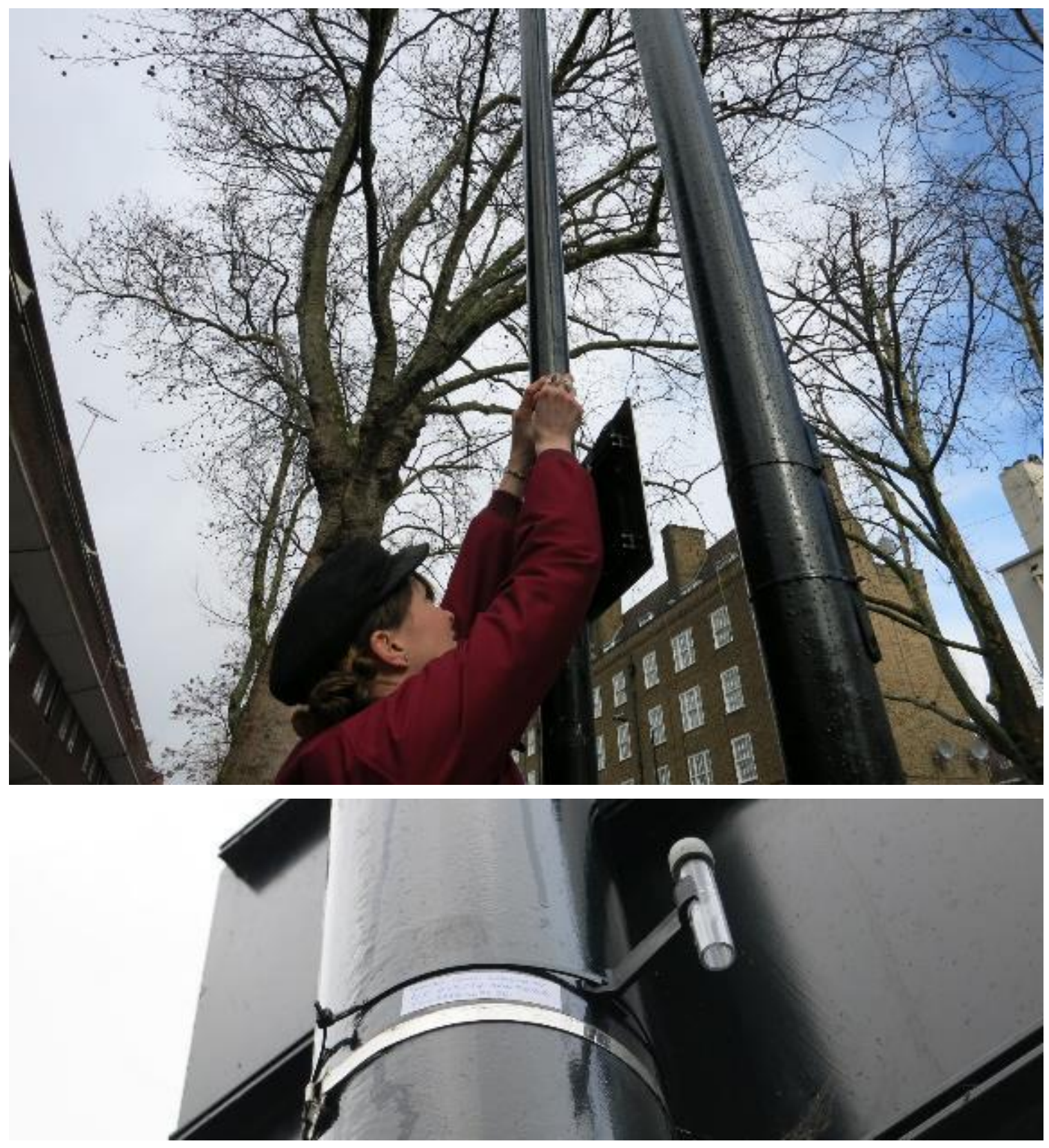
Another neighbour came to say hello and told Tracey how great her initiative to measure air pollution in the neighbourhood was. The neighbour, an elderly lady, chatted with us about her concerns with the air pollution entering her house and explained that there were plans to make the street where we were a lorry passage. Meanwhile, we ran under the shelter of a building nearby because the drizzle was becoming more intense.

Tracey connected to the Mapping for Change application to enter the data. She selected the location on the map, entered the date, distance from road (less than 1 metre), height (2.5 to 3 metres), and time, etc. Afterwards, she went under the rain to attach the diffusion tube to the plastic belt on the lamppost with a tube holder. The grey top of the diffusion tube (see Figure 3) was facing up, and she took out the white cup, facing down. Then, she left a sticker about the activity, with a contact number, on the lamppost by the diffusion tube. She explained to me that the sticker would inform city council workers, like cleaners, and prevent their taking it down. The rain discouraged the neighbours and they left.

At 10:25 we moved to another location. It was an awkward crossing of streets. Tracey realised that the ideal lamppost at the central area was too large for the plastic belts, so they chose a thinner lamppost on a side of the crossing instead. Using the ladder again, they tightened one plastic belt and the tube holder to the lamppost. For a few minutes, the rain stopped. Then, Tracey recorded the data and attached the diffusion tube. She also made notes in her notebook and put the sticker on the plastic belt.

While we headed to the next location, it started to rain again. It was a crossing of streets next to a school. They chose a lamppost next to a bike parking rack, by the road. The rain became heavier and there was a gusty wind that made us feel very cold. Tracey's hands became red and numb from the cold while tightening the plastic belt. She proceeded to enter the data in the application form. I tried to cover both of us with my umbrella, but the wind was blowing too strongly and we were getting wet. We sought shelter in the school. Tracey asked for permission to stay inside for a few minutes and she briefly explained the project. However, we were not allowed to stay in the school building because of the rules. We went outside in the cold and rain. I was disappointed to see that not everybody in the neighbourhood was so enthusiastic or cooperative.

By 10:45, the rain became lighter and the wind stopped. Tracey's friend attached the tube following her instructions: grey cup up, white cup out facing down. They put the sticker on and we moved to the next location. The location was a green area between two schools. Tracey explained that there were plans to renovate that space. They identified a lamppost by the school's fence. Tracey's friend went up the ladder to tighten the plastic belt, but it broke. Tracey gave him another one and cheered him up saying "good work". The rain became heavier again while Tracey was trying to enter the data in the application and making notes in her notebook. Hail and wind burst into a sudden storm. They rushed to put the diffusion tube and sticker on, under the hail, and we all ran to find shelter in a nearby community centre.

It was $11 \mathrm{am}$. We ordered tea in the community centre bar. Our hands were very cold; our clothes were wet. We chatted while drinking hot tea near the radiator. Tracey and her friend told me why it is worth braving the weather and setting up these little plastic tubes: "The air quality is very bad around here." She had been a researcher for five years and worked in a hospital for asthma and respiratory diseases. Now she was doing health communication. 
While we were enjoying this break, Tracey finished entering the data about the last location. Tracey's phone rang: another person would join the team soon.

The rain had stopped and we went out to put up another diffusion tube. The new location was in a street crossing around the corner from the community centre. Tracey had become efficient: she stepped up the ladder, tightened the plastic belt with the tube holder, put the sticker near the plastic belt, recorded the details and held the diffusion tube up, taking the white cup out.

Right after that, we met the new team member at the community centre: a young lady from the Science Museum, who would be documenting the experience and taking pictures. It was time for my goodbye. We had put five diffusion tubes up of a total of twelve and they had planned to stay until $2 \mathrm{pm}$. They would be using the community centre as a base between locations, given the bad weather. At 11:34, I left the group and walked to St Pancras train station with many new questions in my head. There was a cold breeze, but the rain had stopped.

A few days later, I met Louise at her office in University College London. She told me about the preparatory session she organised for this particular study, where she taught participants how to use the Mapping for Change application and how to install the diffusion tubes. Tracey had attended that session, representing the Somers Town neighbourhood in the Camden district, and three other community leaders attended from other neighbourhoods.

The next step after having installed the diffusion tubes was to collect them after four weeks, by $30^{\text {th }}$ March. Louise explained that the dates chosen for installing and collecting the diffusion tubes were not random - they coincided with the official cycle of measurement. Once the diffusion tubes were collected, the participating residents could give them to Louise for her to send them to the lab for analysis, or they could send the diffusion tubes directly to the lab with the stickers that Louise had provided. The lab would send the results of the analysis in about two weeks upon receiving them. The results would show the average $\mathrm{NO}_{2}$ concentration during the four weeks of exposure on the spot where each diffusion tube was placed, and they could be compared among the different locations. The participating community leaders, like Tracey, would have to input the data from the lab into the Mapping for Change system. Then, everybody would be able to see the results on an online map; they would be able to zoom in to their street and see if there was air pollution data nearby. The Mapping for Change system already had public data from several boroughs in London that had been participating in these community-led initiatives.

"Is it possible to compare this data to the official sources? What are residents going to do with it?" I asked her. Louise replied to me with an engaging story. One of the groups that had done the air quality monitoring during the previous month had contacted the local authorities of their district to tell them about the results and their plan to make the data public on the Mapping for Change system. Louise clarified to me that they do not need permission from anyone to make their data public. However, the district authorities were reluctant: they asked the group not to publish the results because they feared that the data was not accurate. After this disappointing reaction from the district authorities, the community leader explained to them that they were advised and taught by researchers from University College London and detailed the procedures they followed. She shared these details to demonstrate that their data was accurate. The district authorities replied that they would have to annualise the results to make them comparable to their official measurements. 
Louise confirmed to me that there is a problem of comparison because the residents only have one month of data.

It is important to note that a precedent has been set by the Barbican neighbourhood, where participants collected data every month during an entire year (Francis and Stockwell 2015), which could be compared with the official measurements. As noted above, the Barbican study was carried out in collaboration with the local authority, and it is a story of success (see the report - Francis and Stockwell 2015 or view in an online documentary https://www.youtube.com/watch?v=YvSuPCxl188). The project "Science in the City" had the financing and support of the City of London, a motivated community leader, and the sustained logistic support of Mapping for Change with follow-up workshops that engaged around 50 local residents. After this successful experience, in summer 2015, Mapping for Change had funding to do a one-month data collection with several groups in the city. But, later, the lack of funding to continue these local initiatives forced the researchers at UCL and Mapping for Change to organise a crowdfunding campaign. Only those communities that paid for the materials and analysis could conduct their air quality monitoring activities.

Louise told me that one of the groups that had participated in the summer 2015 initiative repeated the experience and was very organised through a Facebook page. Other groups were new or there was only one motivated person conducting the bulk of the work, like the case of Tracey in Somers Town.

\section{Discussion}

So far, in this chapter, we have only mentioned in passing the use of real-time low-cost sensors. This is a deliberate decision in the context of a community-led, action research framework. Low-cost sensors are an important area of research, and millions of euros are invested in their development, both by public and private bodies. Yet, despite the ongoing investment over the past decade, they are still not suitable for regular, everyday use that will yield robust, accurate and consistent results - see Kumar et al. (2015) and Lewis and Edwards (2016) for a discussion of their issues. Moreover, their installation is more complex - they require electricity, connectivity and, at this stage of development, the device to be shielded from adverse weather such as the rain and the wind that frequented Somers Town on that wintry day. Moreover, because of the need for calibration, and the amount of data that the device produces, there are major challenges in making the outputs suitable for nonspecialists to interpret in a way that will make the information useful for them. For that reason, the focus of community-led projects, ever since they emerged in the mid-1990s, has been to use reliable methodologies that are easy to use but, at the same time, comparable with official information. It is this aspect that makes the Palmes diffusion tubes so powerful. This is a stable technology that gains acceptance by regulators, local environmental officers and decision makers. By aligning the dates of the monitoring with the official period being used in government-mandated programmes, the results of the community effort are readily comparable with those that are obtained by the local authority. Indeed, as our description above shows, there can be a discussion around the length of the observation (the need for annual monitoring or careful seasonal measurements as offered by Cyrys et al. 2012), but the methodology itself and its results are not questioned or challenged whereas community-led low-cost sensing can be easily dismissed on the basis of the sensors that have been used (Lewis and Edwards 2016). 
Moreover, within the environmental monitoring and decision making processes, these seemingly simple plastic tubes act as more than just a sensor - they are a policy instrument that is used by central and local government in their local air quality management plans. This aspect provides the tubes with political power in the discussion of the result, which other inexpensive methods cannot offer.

Our detailed story of the experience of Tracey in Somers Town is indicative of many issues that are common in community-led air quality campaigns and which we experienced elsewhere.

Firstly, it illustrates some of the difficulties that local residents have in influencing local authorities about their environmental, public health, urban planning and transportation decisions, starting with the doubts about data quality on the part of local authorities and the lack of sustained funding to address environmental issues by local government bodies that are operating under severe budgetary restrictions. This issue of trust and feeling that the measurements are taken in the wrong locations compared to the experience of the people who are living in the area and to the local knowledge about the routes and places of activities are a motivating factor in community-led efforts. For example, notice how Tracey and her neighbours commented on their concerns about potential plans to make a lorry passage in front of a school and the renovation of a space that was a green area between two schools. By taking control over the positioning of the tubes and the installation process itself, the participants gain an understanding of the process of monitoring and the tools that are being used. Arguably, this can increase the understanding of where the data from the local authorities is coming from and the dialogue between communities and local authorities, as happened in the City of London and the London Borough of Lambeth.

Secondly, it provides an illustration of the local focus of the monitoring - noteworthy is the need to guide the participants to position diffusion tubes in a busy road. The reason for this is that, in many communities, the residents perceive the busy road as the boundary of their area, and at the edge of the local neighbourhood area. The need for comparison and benchmarking can be achieved by using local authority monitoring data but, as an intermediary organisation, Mapping for Change guides participants to carry out such data collection so they can compare and contrast the results that they receive from within their area of interest with a nearby pollution source.

Thirdly, we should highlight the nature of the process - it is very common for very few participants to be highly engaged and to be active in the process, in the way that Tracey braved the weather and carried out the installation. However, since it is her locality, other people within the area got involved in either direct help for a short while or by noticing Tracey and asking about her effort. In multiple cases, we have seen that, in feedback sessions, many residents, well beyond those that were active in the installation, join in to see the results and discuss them (see Figure 4). The effort of installing the diffusion tubes is not trivial, and can mean dedication of a significant part of a day in unpleasant weather conditions. It therefore requires well-motivated individuals to lead such efforts, which is the case in many locations. Yet, it is this wider community interest and support that makes their effort worthwhile and sustainable, in the case of donating to a common fund to maintain the activity. 
Figure 4-Feedback session at UCL with community members.
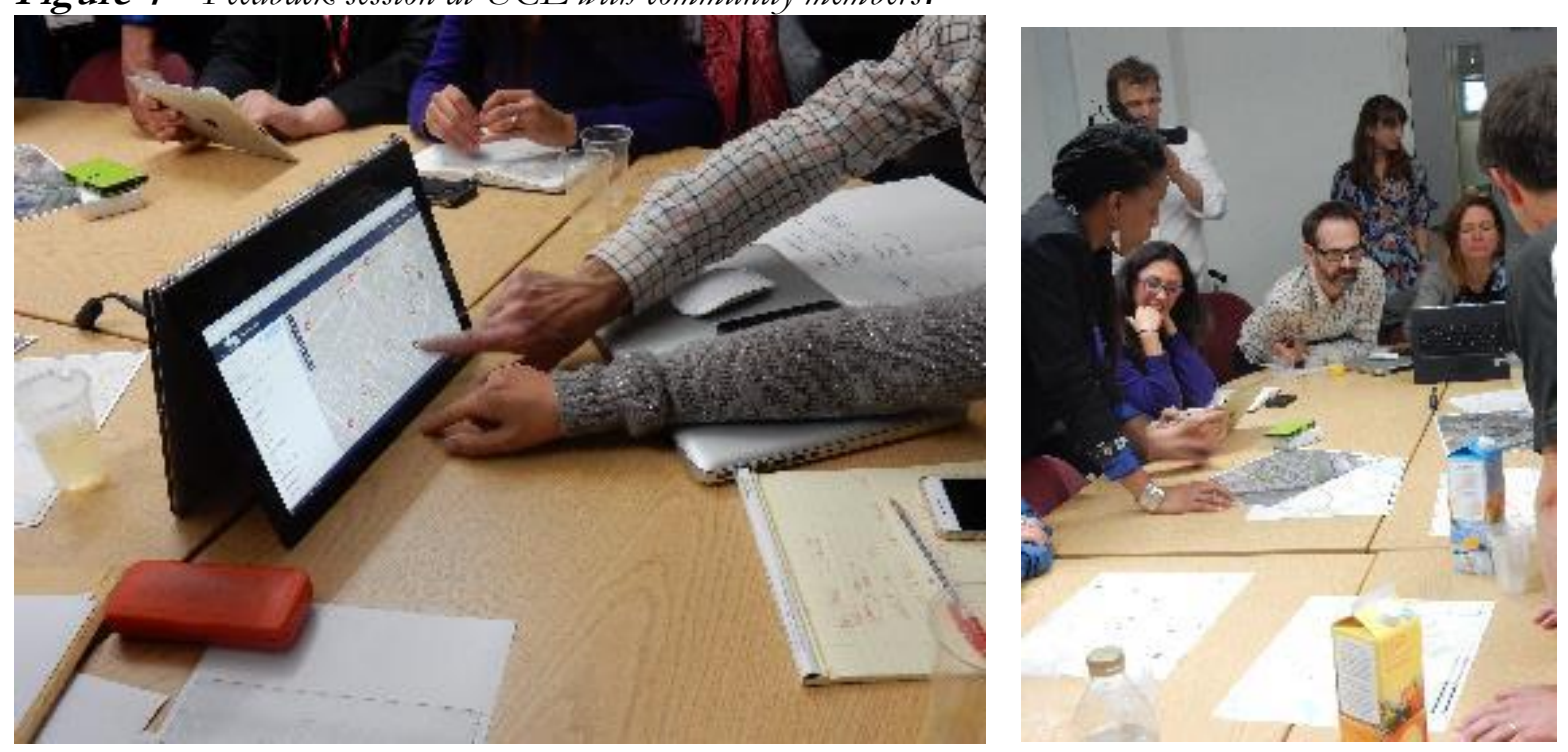

Finally, the Somers Town installation demonstrates the way in which local problem solving and technology are being used in these community-led campaigns. Notice how Tracey confronted and solved the issue of installing tubes in wide and narrow lampposts, or the use of the Mapping for Change community maps system to record the location of the installation - using her smartphone as a Wi-Fi hotspot and her computer to enter the data while sheltering from the rain (the resulting map is shown in Figure 4a). Over the years, we have seen many examples of local problem solving and innovations - such as decisions to install diffusion tubes on the balconies in the Barbican. This is an important aspect of community-led citizen science efforts, which provides background to both learning and creativity (see Jennett et al. 2016 and Jennett et al. 2017).

Table 1- Main characteristics of community-led monitoring.

\begin{tabular}{|l|l|}
\hline Aspect & Detail \\
\hline Organisation & $\begin{array}{l}\text { Ad hoc, or an organisation with other remit (e.g. residents' association, friends } \\
\text { of a local park). }\end{array}$ \\
\hline Project design & $\begin{array}{l}\text { The problem is set by the community and the information that emerges from } \\
\text { it is being used by them, although the analysis might be carried out by external } \\
\text { expert. The project will be action oriented. }\end{array}$ \\
\hline Geographical scope & $\begin{array}{l}\text { Local or hyperlocal - a neighbourhood, and sometimes a specific street. } \\
\text { Territoriality can play a role in the location of sampling and decisions on } \\
\text { where the measurements will take place. }\end{array}$ \\
\hline Length of time & $\begin{array}{l}\text { Limited - the participants use their free time for participation, and usually } \\
\text { expect results within a framework of one or two months. }\end{array}$ \\
\hline $\begin{array}{l}\text { Resources - } \\
\text { personnel }\end{array}$ & $\begin{array}{l}\text { Community-led studies can benefit from the availability of local volunteers } \\
\text { who are motivated in addressing the problem. There is a potential for a wide } \\
\text { range of skills within the community (e.g. a resident with engineering or } \\
\text { science background) although that could be a challenge. Usually a small group } \\
\text { of highly committed residents will lead the project and carry it out. }\end{array}$ \\
\hline
\end{tabular}




\begin{tabular}{|l|l|}
\hline $\begin{array}{l}\text { Resources - } \\
\text { equipment }\end{array}$ & $\begin{array}{l}\text { Usually a limiting factor in the ability to access and operate environmental } \\
\text { monitoring equipment, beyond widely available technologies (e.g. } \\
\text { smartphones), and therefore need to work with experts and universities to } \\
\text { access them and operate them. }\end{array}$ \\
\hline $\begin{array}{l}\text { Resources - } \\
\text { funding }\end{array}$ & $\begin{array}{l}\text { Usually very limited, with potential for very limited sums to be raised locally in } \\
\text { the case of marginalised groups. Effective use of small grants to carry out } \\
\text { monitoring. }\end{array}$ \\
\hline $\begin{array}{l}\text { Problem solving, } \\
\text { learning, creativity }\end{array}$ & $\begin{array}{l}\text { Integral part of community-led projects is an accelerated learning of the } \\
\text { environmental issue that is the focus of the investigation, identifying locations } \\
\text { for sampling, and solving problems in the different stages of the project. }\end{array}$ \\
\hline Impact & $\begin{array}{l}\text { The impact of the project will depend on the community's ability to mobilise } \\
\text { wider political and social resources to address the local problem. Can be } \\
\text { especially problematic when the environmental issue is addressed at national } \\
\text { level (e.g. regulations to encourage recycling or incineration) while the } \\
\text { problems are hyperlocal. }\end{array}$ \\
\hline
\end{tabular}

\section{Conclusions}

In this chapter, we provided a detailed account of the experience of community-led air quality monitoring that is done within the context of community concern over local air pollution from traffic and its impact on their health. We have discussed how changes in the context of environmental decision making, awareness of environmental justice and in technology enabled a new wave of community-led monitoring efforts.

As we have seen, the use of accessible and reliable sensing tools, such as the air capture buckets or diffusion tubes, provides the ability for community members to use their local knowledge to collect the information at the location that matters to them, and to understand local conditions. A recent campaign by Friends of the Earth demonstrated that diffusion tubes can also be scaled to a national campaign in the UK (see FoE 2017), while the London Sustainability Exchange provided guidance for their use to primary schools (LSx 2013).

We also pointed to the deceiving surface simplicity that the use of these tools provides they allow for deep local engagement, an understanding of the process of measuring and understanding air pollution issues, and a potential foundation for a discussion between communities and local decision makers on the basis of scientific evidence that both sides accept. In what might seem contradictory, at first sight, the use of agreed-upon devices through citizen science and community-led monitoring can reduce the conflict between residents and local environmental management authorities, improve the process of air quality monitoring and offer new solutions to local issues.

Community-led air quality monitoring is not being offered as a panacea or as a replacement for government-mandated monitoring, but as an enhancement and as a way to address specific emerging issues, such as an increase in traffic due to a temporary construction project, or in addressing ongoing concerns such as the impact of queuing traffic. This form of citizen and stakeholder participation can also integrate into Health Impact Assessments of urban and transport planning projects, to address power unbalance, select scenarios for monitoring and evaluation, and identify health effects and vulnerable populations (Nieuwenhuijsen et al. 2017). 


\section{Acknowledgements}

Thanks to Louise Francis, managing director of Mapping for Change, for sharing her valuable insights and practical knowledge acquired during many years of working with communities in London, and to Tracey for allowing us to join her on the day. This chapter benefited from the European Union's Seventh Framework Programme (FP7/2007-2013) under grant agreement EveryAware (award 265432), and the EU Horizon 2020 research and innovation programme under the Marie Sklodowska-Curie grant (award 656439), and Doing it Together Science (award 709433) as well as the UK's Engineering and Physical Sciences Research Council (award EP/I025278/1).

\section{References}

Bonney, R., Shirk, J.L., Phillips, T.B., Wiggins, A., Ballard, H.L., Miller-Rushing, A.J. and Parrish, J.K., 2014. Next steps for citizen science. Science, 343(6178), pp.1436-1437.

Bullard, R.D. and Wright, B.H., 1993. Environmental Justice for All: Community Perspectives on Health and Research. Toxicology and Industrial Health, 9(5), pp.821-841.

Corburn, J., 2005. Street Science: Community Knowledge and Environmental Health Justice (Urban and Industrial Environments).

Cyrys, J., Eeftens, M., Heinrich, J., Ampe, C., Armengaud, A., Beelen, R., Bellander, T., Beregszaszi, T., Birk, M., Cesaroni, G. and Cirach, M., 2012. Variation of NO 2 and NO x concentrations between and within 36 European study areas: results from the ESCAPE study. Atmospheric Environment, 62, pp.374-390.

Fenger, J., 2009. Air pollution in the last 50 years - From local to global. Atmospheric Environment, 43(1), pp.13-22.

Friends of the Earth, 2017. Unmasked: the true story of the air you're breathing, Friends of the Earth, London, p.23. Available at: https://cdn.foe.co.uk/sites/default/files/downloads/FoE Unmasked Report 2017.pdf [Accessed August 2017]

Francis, L. and Stockwell, H., 2015. Science in the City: Monitoring air quality in the Barbican. [online] London: Mapping for Change, pp. 33, 34. Available at: https://www.cityoflondon.gov.uk/business/environmental-health/environmentalprotection/air-quality/Documents/barbican-final-report-13012015.pdf [Accessed August 2017]

Haklay, M., 2013. Citizen Science and Volunteered Geographic Information - overview and typology of participation. In Sui, D.Z., Elwood, S. and M.F. Goodchild (eds.), Crowdsourcing Geographic Knowledge: Volunteered Geographic Information (VGI) in Theory and Practice. Berlin: Springer, pp.105-122.

Haklay, M., 2017. The Three Eras of Environmental Information: The Roles of Experts and the Public. In Participatory Sensing, Opinions and Collective Awareness (pp. 163-179). Springer International Publishing.

Haklay, M.E., 2003. Public access to environmental information: past, present and future. Computers, Environment and Urban Systems, 27(2), pp.163-180.

Heidorn, K.C., 1978. A chronology of important events in the history of air pollution meteorology to 1970. Bulletin of the American Meteorological Society, 59(12), pp.1589-1597.

Jennett, C., Kloetzer, L., Schneider, D., Iacovides, I., Cox, A., Gold, M., Fuchs, B., Eveleigh, A., Methieu, K., Ajani, Z. and Talsi, Y., 2016. Motivations, learning and creativity in online citizen science. Journal of Science Communication, 15(3).

Jennett, C., Kloetzer, L., Cox, A.L., Schneider, D., Collins, E., Fritz, M., Bland, M.J., Regalado, C., Marcus, I., Stockwell, H. and Francis, L., 2017. Creativity in Citizen Cyberscience. Human Computation, 3(1), pp.181-204. 
Kuklinska, K., Wolska, L. and Namiesnik, J., 2015. Air quality policy in the US and the EU - a review. Atmospheric Pollution Research, 6(1), pp.129-137.

Kumar, P., Morawska, L., Martani, C., Biskos, G., Neophytou, M., Di Sabatino, S., Bell, M., Norford, L. and Britter, R., 2015. The rise of low-cost sensing for managing air pollution in cities. Environment International, 75, pp.199-205.

Laundon, J.R., 1967. A study of the lichen flora of London. The Lichenologist, 3(3), pp.277-327.

Lewis, A. and Edwards, P., 2016. Validate personal air-pollution sensors. Nature, 535(7610), pp.29-32.

London Sustainability Exchange (LSx), 2013. Cleaner Air 4 Primary Schools toolkit. Available https://www.london.gov.uk/sites/default/files/ca4s toolkit.pdf [Accessed August 2017]

Lowenthal, D., 1990. Awareness of Human Impacts: Changing Attitudes and Emphases. In: Turner B.L., editor. The Earth as Transformed by Human Action: Global and Regional Changes in the Biosphere over the past 300 Years. Cambridge; New York: Cambridge University Press with Clark University, pp.121-135.

McGlade, J., 2008. Environmental information and public participation, available at http://www.eea.europa.eu/media/speeches/environmental-information-and-publicparticipation [Accessed February 2014]

Nieuwenhuijsen, M.J., Khreis, H., Verlinghieri, E., Mueller, N. and Rojas-Rueda, D., 2017. Participatory quantitative health impact assessment of urban and transport planning in cities: A review and research needs. Environment International, 103, pp.61-72.

Ottinger, G., 2010. Buckets of resistance: Standards and the effectiveness of citizen science. Science, Technology, \& Human V alues, 35(2), pp.244-270.

Parry, N. and Rimmington, B., 2013. Citizen science - local air quality; local action. Chemical Hazards and Poisons Report, p.45.

Scott, D. and Barnett, C., 2009. Something in the air: civic science and contentious environmental politics in post-apartheid South Africa. Geoforum, 40(3), pp.373-382.

Sella, A., 2016. Palmes' tube, Chemistry World, 1 November 2016.

Shirk, J. L., Ballard, H. L., Wilderman, C. C., Phillips, T., Wiggins, A., Jordan, R., McCallie, E., Minarcheck, M., Lewenstein, B. V., Krasny, M. E. and Bonney, R., 2012. Public participation in scientific research: a framework for deliberate design. Ecology and Society, 17(2).

Tregidgo, D.J., West, S.E. and Ashmore, M.R., 2013. Can citizen science produce good science? Testing the OPAL Air Survey methodology, using lichens as indicators of nitrogenous pollution. Environmental Pollution, 182, pp.448-451.

United Nations, 1992, Agenda 21, United Nations, Rio de Janeiro.

WCED and Brundtland, G. H., 1987. Our Common Future. Oxford, UK: Oxford University Press. 